\title{
Influence of Seasonal Variability of the Wind Stress Vorticity on the Structure of the Black Sea Circulation
}

\author{
A. A. Pavlushin*, N. B. Shapiro, E. N. Mikhailova \\ Marine Hydrophysical Institute, Russian Academy of Sciences, Sevastopol, Russian Federation \\ *e-mail: pavlushin@mhi-ras.ru
}

The present paper represents the results of two experiments on numerical modeling (within the framework of the two-layer eddy-resolving model) of the Black Sea large-scale circulation under the influence of the seasonally-variable wind. The actual bottom topography is taken into account in the model. The motion is excited only by the tangential wind stress with a non-zero vorticity. The energy loss is due to the bottom friction, the friction at the layers' interface and the horizontal turbulent viscosity. In one of the experiments under consideration, the wind stress vorticity changes its sign depending on the season (in winter it is cyclonic, in summer - anticyclonic), but remains constant in space. In the other experiment, the field of the tangential wind stress is preset (according to the modern notions on its spatial variability) in such a way that over the sea western half there is the zone of anticyclonic vorticity, the area and intensity of which vary throughout the year. In both cases, the circulation in the Black Sea is periodically divided into two large cyclones - the "Knipovich glasses". However, due to the western intensification of currents caused by the $\beta$-effect, the wind stress with spatially uniform vorticity results in formation of a cyclonic cycle of extremely high intensity in the southwestern part of the basin. In the other experiment that takes into account spatial variability of the wind stress vorticity above the sea, namely, anticyclonic vorticity of the wind tangential stress over the basin western part, the obtained circulation quite corresponds to the observational data.

Keywords: the Black Sea, eddy-resolving model, large-scale circulation, wind stress vorticity, seasonal variability, "Knipovich glasses".

Acknowledgments: the research is carried out within the framework of the State Order No. 0827-20140011 "Research of the Regularities of Changes in theCondition of the Marine Environment on the Basis of Operational Observationsand Data of the System of Diagnosis, Prognosis and Reanalysis of the Condition of Marine Areas (Operational Oceanography).

For citation: Pavlushin, A.A., Shapiro, N.B. and Mikhailova, E.N., 2018. Influence of Seasonal Variability of the Wind Stress Vorticity on the Structure of the Black Sea Circulation. Physical Oceanography, [e-journal] 25(5), pp. 345-358. doi:10.22449/1573-160X-2018-5-345-358

DOI: $10.22449 / 1573-160 X-2018-5-345-358$

(C) 2018. A. A. Pavlushin, N. B. Shapiro, E. N. Mikhailova

(C) 2018, Physical Oceanography

\section{Introduction}

Numerical experiments were carried out further to a series of studies on the effect of individual factors on the formation and variability of large-scale circulation and vortex structures in the Black Sea caused by wind. Their results are discussed in the present paper. It is to be recalled that for the numerical simulation a two-layer eddy-resolving model based on the primitive hydrodynamic equations of the ocean is used. The model considers a sea basin consisting of two layers of water of different density that do not mix with each other. The movement of water in the sea is excited only by the tangential wind stress effect; the energy sink isexecuted due to horizontal turbulent viscosity, bottom friction and friction between the layers at theirsection boundary. A more detailed description of the model is available in [1, 2]. 
As was shown [2, 3], a necessary condition for the formation of the circulation known in the Black Sea, is the compulsory consideration of such factors in the model as the long-term effects of wind with cyclonic vorticity, nonlinearity, density stratification (bilayer), $\beta$-effect and bottom topography. In this case, the coefficients of horizontal viscosity, bottom friction and friction between the layers should be set sufficiently small so as not to impede the hydrodynamic instability processes, leading to eddy formation. In the previous experiments, under the effect of stationary wind and the aforementioned factors, the characteristic features of the Black Sea circulation were obtained. They are the jet meandering current located above the continental slope - the Black Sea Rim Current (Rim Current), mesoscale quasi-stationary anticyclonic eddies arising between the Rim Current and the coast (the Batumi, Sevastopol, etc.) [4-7]. The Rim Current meanders were long waves propagating along the current core with a phase velocity of 5-10 $\mathrm{cm} / \mathrm{s}$ along with mesoscale eddies movingwith them.

Note that in the experiments with stationary wind the well-known phenomenon of the Black Sea circulation - its division into two separate closed gyres failed to be reproduced. Such a pattern of Black Sea currents is called "Knipovich glasses" and was repeatedly confirmed in the works of various authors based on the analysis of averaged dynamic topography fields $[4,5,8]$.

All the previous experiments used the tangential wind stress field $\boldsymbol{\tau}(x, y)$ with cyclonic vorticity (rot $\tau>0$ ), which did not vary in time and was constant over the entire sea surface as the exciting force. In fact, the wind vorticity over the Black Sea during the year does not remain constant and even changes sign during summer months [9, 10]. In addition, the $\tau$ vorticity is uneven in space [11, 12], which can also affect the structure of currents in the sea.

\section{Numerical experiments}

In this paper, the results of two experiments - S1 and S2 are analyzed. There, unlike the previous calculations, the field $\boldsymbol{\tau}(x, y)$, which varies throughout the year, is used for atmospheric forcing. The depth of the interface at the initial moment of time at rest is $175 \mathrm{~m}$, the $r_{2}, r_{3}$ coefficients in the expression for the bottom friction $\left[r_{2}+r_{3}\left|\mathbf{u}_{2}\right|\right] \mathbf{u}_{2}$ are $1 \cdot 10^{-3}$ and $2 \cdot 10^{-3} \mathrm{~cm} / \mathrm{s}$, respectively, the coefficient of biharmonic turbulent viscosity is $A_{B}=4 \cdot 10^{16} \mathrm{~cm}^{4} / \mathrm{s}^{4}$. The coefficient $r_{1}$ for friction between the layers $r_{1} \cdot\left(\mathbf{u}_{1}-\mathbf{u}_{2}\right)$ is taken to be $2 \cdot 10^{-4} \mathrm{~cm} / \mathrm{s}$.

In the $\mathrm{S} 1$ experiment, the field vorticity $\boldsymbol{\tau}$ is set constant in space, but varies in time according to aharmonic law. There is a cyclonic vorticity of the tangential wind stress with a maximum in early January, and in summer the sign of rot $\boldsymbol{\tau}$ changes to the opposite one for nine months above the sea (Fig. 1, $a-c$ ). The maximum anticyclonicwind vorticity falls on July 1.

In the S2 experiment in the $\boldsymbol{\tau}(x, y, t)$ field, the features of the distribution and variability of the wind vorticity over the Black Sea, described by V. V. Efimov, A. V. Yurovsky [11], were taken into account. The authors showed that between the eastern and western parts of the Black Sea there are significant differences in the seasonal variation of rot $\boldsymbol{\tau}$. The cyclonic regime of wind vorticity with a maximum in winter months is observed in the eastern part of the sea throughout the year. Above the western part of the sea, for the most part of the year, the wind vorticity is anticyclonic, and the cyclonic one appears only in winter. These 
features, according to the authors and other researchers [13, 14], are associated with the effectof the troposphere of the monsoon mechanism and coastal orography on the wind vorticity in the lower part. Simulating the field $\boldsymbol{\tau}(x, y, t)$, the data on the average and maximum values of rot $\boldsymbol{\tau}$ from [10] were also taken into account.

Поле $\tau(x, y, t)$ в эксперименте $\mathrm{S} 1$

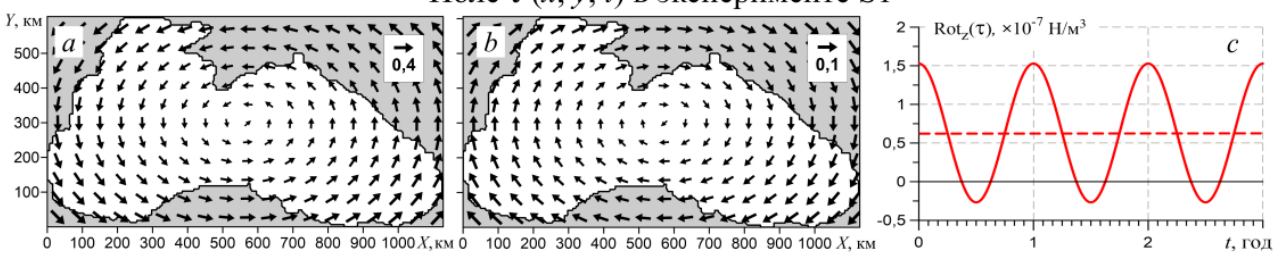

Поле $\tau(x, y, t)$ в эксперименте $\mathrm{S} 2$
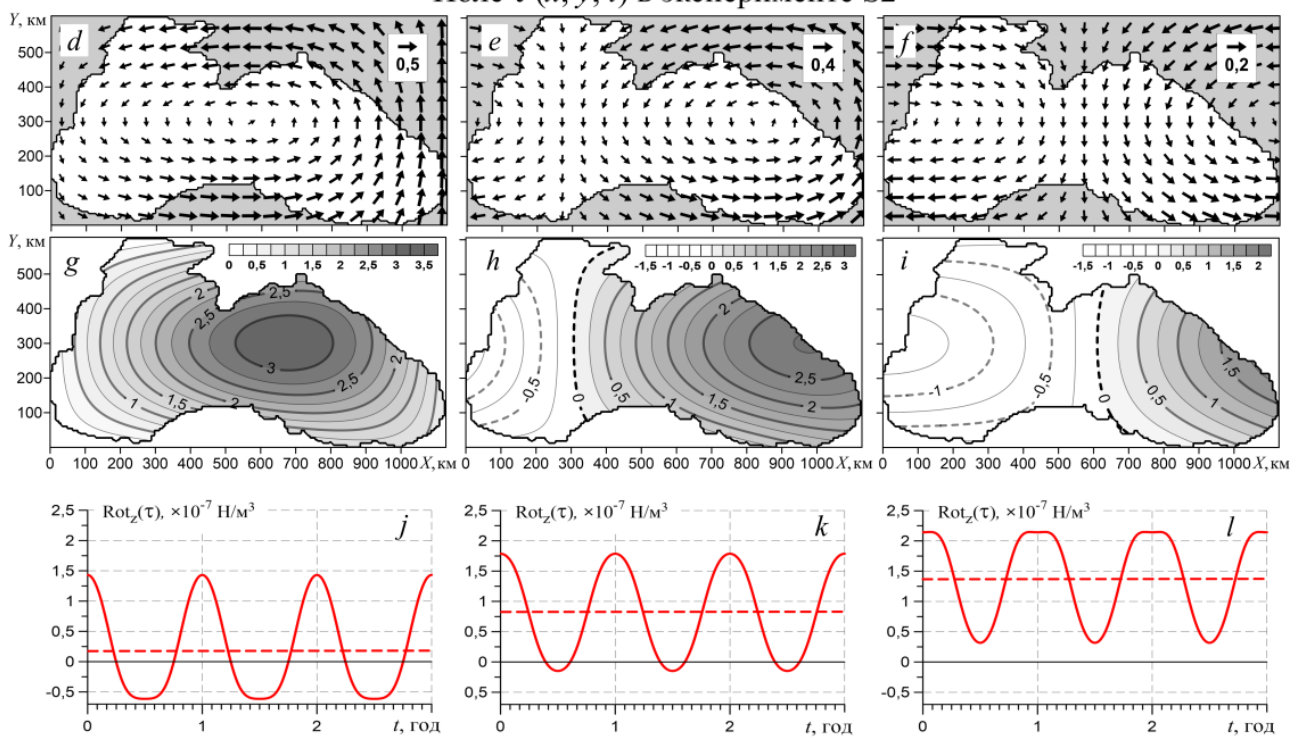

Fig. 1. Instant fields $\tau, \mathrm{cm}^{2} / \mathrm{s}^{2}$, in the S1 experiment: January, $1(a)$, July, $1(b)$; in the S2 experiment: January, $1(d)$, April, 1 and October, $1(e)$, July, $1(f)$. The scale of $\tau$ is in the upper right corner. Instant fields rot $\tau, 10^{7} \mathrm{H} / \mathrm{m}^{3}$, in the S1 experiment: January, $1(\mathrm{~g})$, April, 1 and October, $1(\mathrm{~h})$, July, $1(\mathrm{i})$. Variation in time of rot $\tau$ in S1 (c), variation in time of average rot $\tau$ in S2 over the whole sea $(k)$; for the western half of the sea $x<500 \mathrm{~km}(j)$, for the eastern half of the sea $x \geq 500 \mathrm{~km}(l)$. The dotted lines on $c, j, k, l$ denote annual average vorticity of rot $\tau$

The $\boldsymbol{\tau}$ fields used in the S2 experiment and the corresponding distributions of rot $\boldsymbol{\tau}$ for three time points are shown in Fig. 1, $d-i$. The $\tau$ vorticity averaged over the whole sea area has a cyclonic orientation in autumn, winter and spring months (Fig. 1, $k$ ). Over the eastern half of the sea throughout the year, the $\boldsymbol{\tau}$ vorticity is cyclonic rot $\boldsymbol{\tau}>0$ (Fig. $1, j$ ), and over its western half the sign rot $\tau$ changes depending on the season: in the cold half of the year rot $\tau>0$, in the warm half $-\operatorname{rot} \tau<0$.

Long time numerical integration is carried out from the state of rest with a time step $\Delta t=90 \mathrm{~s}$, space steps $\Delta x=\Delta y=3 \mathrm{~km}$. During the experiments, to control the solution output to the statistically equilibrium mode, the area average values of the available potential DPE and kinetic energy in each $K E_{1}, K E_{2}$ layer are used. 


$$
D P E=\left\langle\rho_{1} g^{\prime}\left(h_{1}^{2}-h_{0}^{2}\right) / 2\right\rangle, K E_{1}=\left\langle\rho_{1} h_{1}\left(u_{1}^{2}+v_{1}^{2}\right) / 2\right\rangle, K E_{2}=\left\langle\rho_{2} h_{2}\left(u_{2}^{2}+v_{2}^{2}\right) / 2\right\rangle,
$$

where $\rho_{1}, \rho_{2}$ is water density in the layers; $h_{0}$ is the upper layer thickness at rest; $h_{1}$, $h_{2}$ is the thickness of the upper and lower thickness, respectively; $u_{1}, v_{1}$ are the velocity components in the upper layer; $u_{2}, v_{2}$ are the velocity components in the lower layer; angle brackets mean the area averaging.

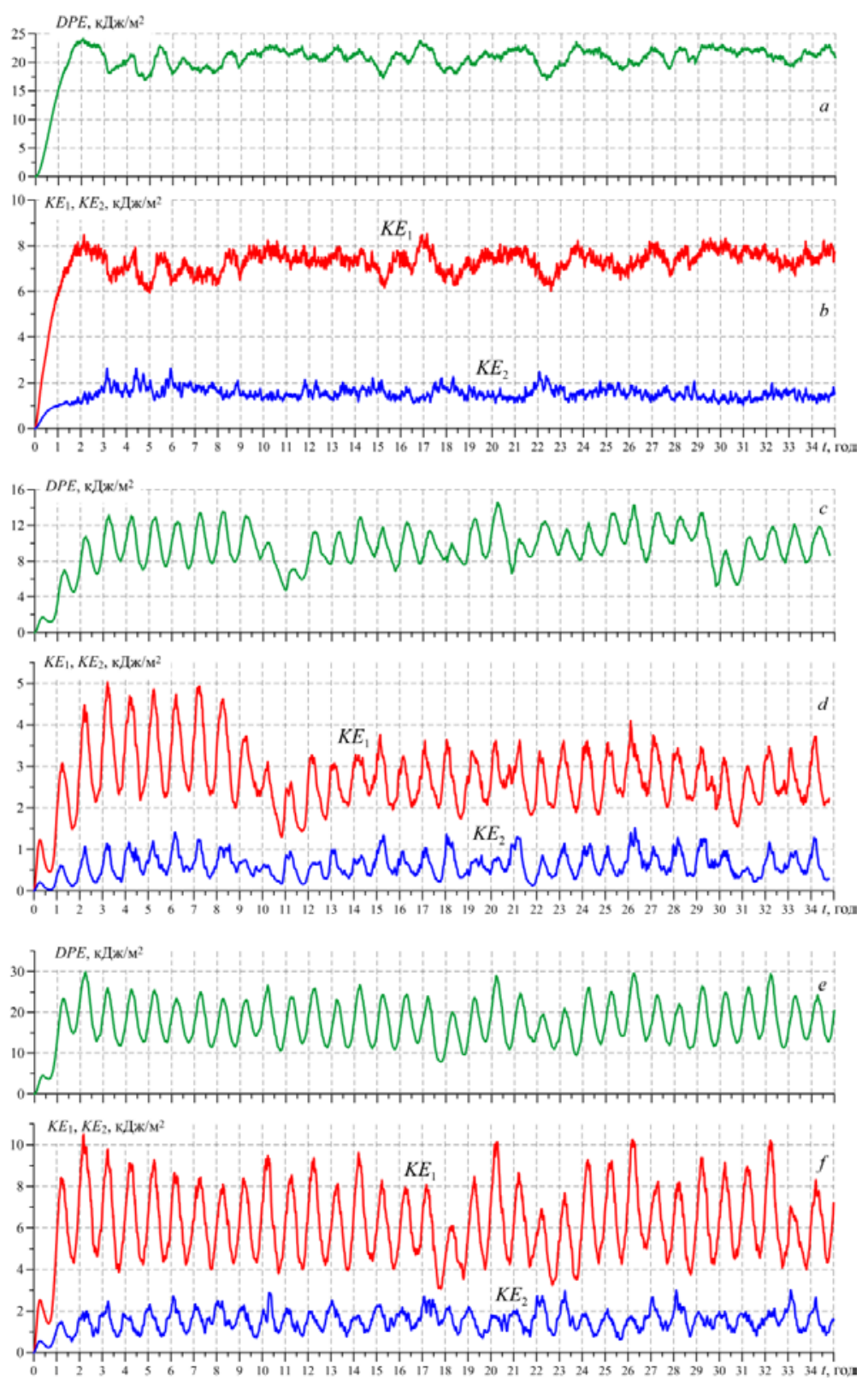

Fig. 2. Graphs of the square-averaged energy in the experiment with the stationary wind $\boldsymbol{\tau}(a, b)$ and the seasonal variation in the $\mathrm{S} 1(c, d)$ and $\mathrm{S} 2(e, f)$ experiments 
Time variations of $D P E, K E_{1}, K E_{2}$ have their own distinctive features in each experiment, while in their temporal progress several characteristic periods can be distinguished. In the initial period (spin-up) there is an accumulation of energy and the formation of currents. In the current velocities reached values which nonlinear effects began to appear at, leading to the appearance of hydrodynamic instability and the formation of mesoscale eddies. At the same time, the inflow of energy into the sea from the wind sharply decreased, which, in turn, led to a decrease in DPE and $K E_{1}$.

After spin-up, comes a period during which the mutual adaptation of the current fields in different layers between themselves and with the $\tau$ field takes place. Its characteristic feature is the circulation formation in the lower layer, accompanied by an increase in $K E_{2}$. At the end of the adaptation period, the solution enters the statistical equilibrium mode, at which the average characteristics calculated in the model remain almost constant with further integration over time. Note that in the experiments with stationary wind the indicated periods are well distinguished. Fig. 2, $a$ and Fig. 2, $b$ show the graphs of $D P E, K E_{1}, K E_{2}$, obtained under exposition to a stationary field $\tau$, having a constant cyclonic vorticity rot $\boldsymbol{\tau}=$ $=1,53 \cdot 10^{-7} \mathrm{~N} / \mathrm{m}^{3}$. It can be seen that the spin-up period is two years, and by the beginning of the fourth year the solution goes to a statistically equilibrium mode. In this mode, in the experiment with stationary wind two following types of wavelength oscillations are observed on the energy graphs (Fig. 2): the first one - with a period of about 50 days, due to the formation of mesoscale eddies during the meandering of a circular jet current in the upper layer, and the second - with a significantly longer period from one to two years, associated with dynamic processes in the lower layer, more inertial due to its considerable thickness [2].

\section{Results of the S1 and S2 numerical experiments}

Unlike the experiments with constant rot $\boldsymbol{\tau}$, where the energy variation was determined by self-oscillating processes, in the S1 and S2 experiments, the lowfrequency variability of the model characteristics is set externally by the seasonal variation of wind vorticity. This leads to the fact that on the graphs of energy characteristics (Fig. 2, $c-f$ ) it is more difficult to determine the boundaries between the periods of spin-up, adaptationand statistical equilibrium. The point is that against the background of the seasonal variations of these valuesbeing large in amplitude, the variability associated with the processes of mesoscale eddy formation is less visible than in the experiment with constant rot $\boldsymbol{\tau}$. Judging by the $K E_{2}$ graphs, it can be said that in the S1 and S2 experiments the spin-up period lasts two years, after which the solution in the S2 experiment almost immediately reaches the statistically equilibrium mode, and in the S1 experiment the period of statistical equilibrium takes place only after the $12^{\text {th }}$ year. This conclusion follows from the analysis of $K E_{1}$ variability (Fig. 2, d).

In the S1 experiment, during the first eight years, a circulation in the basin is formed. During it there is a circular jet current in the upper layer of the sea (analogous to the Rim Current) that propagates along the continental slope along its entire perimeter. The instant $h_{1}$ and $\mathbf{u}_{1}$ fields, characteristic for this period, constructed for several moments of time in the sixth year are shown in Fig. 3. It is noteworthy that there is a good correspondence between the spatial distribution of 
the thickness of the upper layer and the current field in it. As can be seen in the figure, the circular current has a pronounced meandering character. Under the effect of the seasonal variability of wind vorticity, the number and amplitude of meanders increase in summer period (Fig. 3, $e-h$ ). In late autumn and in winter with increasing of cyclonic vorticity $\boldsymbol{\tau}$, the Rim Current meandering almost ceases (Fig. 3, $a, b, i$ and $j$ ). The average velocities of currents in the upper layer in the Rim Currentarea are $40-60 \mathrm{~cm} / \mathrm{s}$ in winter and $35-45 \mathrm{~cm} / \mathrm{s}$ in summer. Note that the cyclonic nature of the circulation in the sea is maintained throughout the year, despite that in summer over the sea, the wind stress vorticity is anticyclonic.

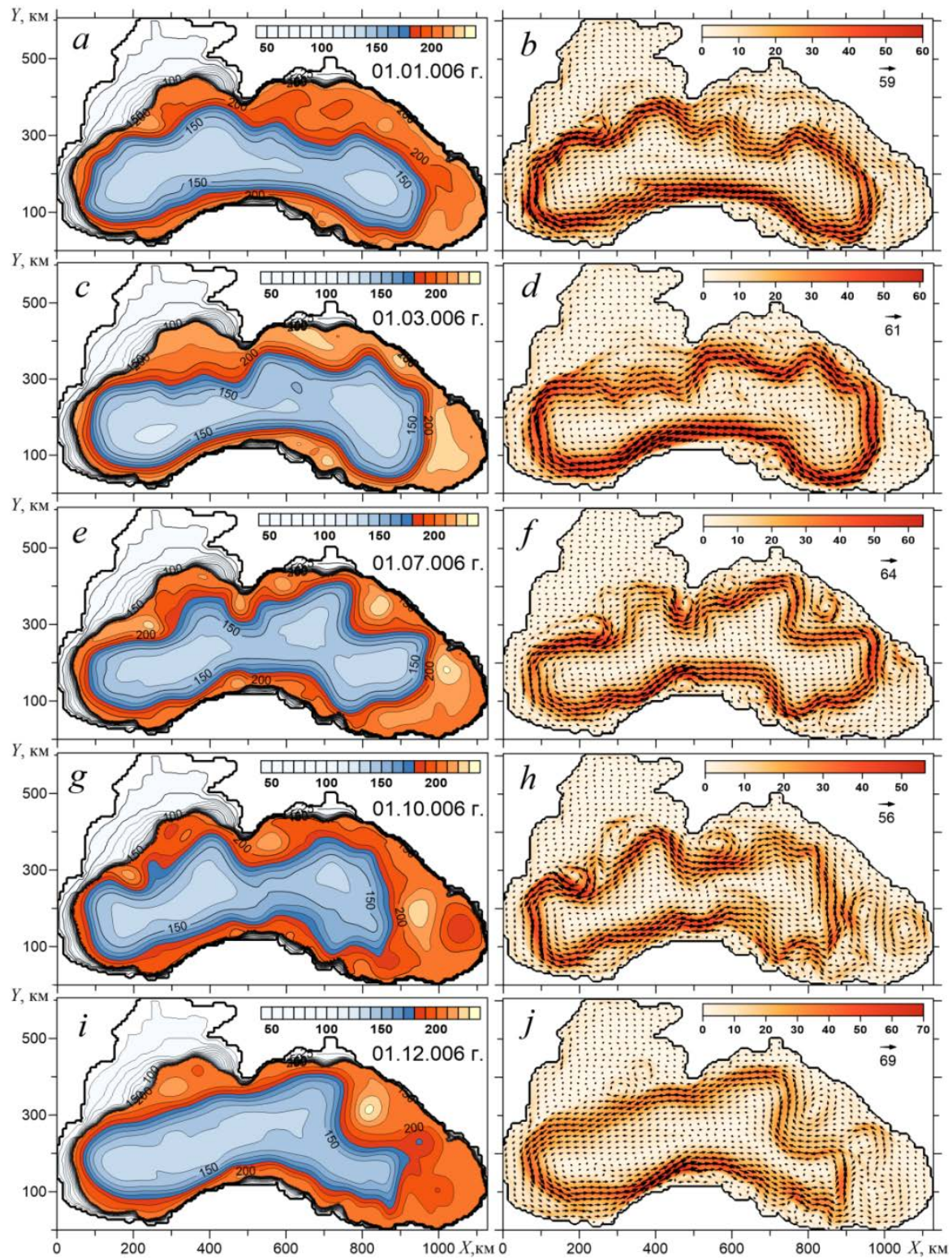

Fig. 3. Instant fields in the $\mathrm{S} 1$ experiment: $h_{1}, \mathrm{~m}(a, c, e, g, i), \mathbf{u}_{1}, \mathrm{~cm} / \mathrm{s}(b, d, f, h, j)$. The dates are given on the maps $h_{1}$; on the maps $\mathbf{u}_{1}$ the scale arrow corresponds to the maximum velocity 
In the lower sea layer in the considered period, as a result of the dynamic interaction of the layers, the currents mainly directed along the isobaths are formed. The average current velocity is $3-5 \mathrm{~cm} / \mathrm{s}$. In the continental slope area in the field of currents, trapped waves are generated, propagating, like currents, in a cyclonic direction. The Rossbybarotropic waves are formed in the deep-sea part [2, 15, 16], which contribute to the transfer and accumulation of the cyclonic vorticity of the current velocity field in the western part of the basin. Note that with seasonal variability of wind vorticity, the processes of wave formation and energy transfer to the lower sea layer are more intense than in experiments with constant vorticity. Ultimately, in the S1 experiment, after nine years of calculations, it leads to the current field reconstruction. It results inthe formation of an intense cyclonic eddy in the southwestern part of the sea and considerable weakening of the circulation in the eastern part of the basin. This process is reflected in the behavior of the total energy, as can be seen in Fig. 2, $c, 2, d$.

Hereinafter, starting from the $13^{\text {th }}$ year and until the end of the calculations in experiment $\mathrm{S}$, the circulation variation within the annual cycle occursthe same type, which is characteristic of the statistical equilibrium mode. The instant $h_{1}$ and $\mathbf{u}_{1}$ fields, characteristic for this period, are shown in Fig. 4. The main feature of circulation in the studied period is a powerful cyclonic eddy presence in the upper layer of the sea in its southwestern part. This eddy remains throughout the entire time and has a significant effect on the energy input from the wind and the formation of the current field. Under its effect, in winter period, an anticyclonic circulation (Fig. 4, $a$, $4, b$ ) is formed near the Anatolian coast, contributing to the division of the general circulation into two parts. The anticyclonic eddy does not disappear completely even at the moment of maximum positive rot $\boldsymbol{\tau}$. When the cyclonic vorticity $\boldsymbol{\tau}$ is weakened and its sign changes, the anticyclone expands and occupies a significant area of the sea between Turkey and Crimea (Fig. $4, f, 4, g$ ).

At this period in the eastern Black Sea, there is another cyclonic gyre, larger in size but less in intensity than a cyclone in the southwest. The cycle increases in autumn-winter period and weakens in summer in full accordance with the seasonal variation of the vorticity $\tau$ (Fig. $4, f, 4, g$ ). In spring to the right of this cyclone, near the eastern coast, an anticyclonic eddy (the Batumi anticyclone) is formed, which subsequently moves from its place of formation towards the northwest (Fig. 4, 4, c, 4, e, 4, g, 4, i). The lifetime of this anticyclonic formation is more than six months, the speed of movement is about $2 \mathrm{~cm} / \mathrm{s}$. The results obtained are consistent with the data of satellite observations of the Batumi anticyclone dynamics given in [17].

In the lower layer of the sea in the S1 experiment, the circulation in the considered period is an extensive cyclonic gyre with two centers corresponding to the cyclones of the upper layer. In autumn and winter, the circulation in the lower layer increases, and in the summer it weakens. The currents propagate mainly along the isobaths with an average velocity of $2-5 \mathrm{~cm} / \mathrm{s}$. They are superimposed by waves captured by the continental slope, a kind of topographic Rossby waves [15]. Note that the Rossbybarotropic waves, observed in the S1 experiment for the first nine years, do not appear in subsequent years.

In whole, using the S1 experiment, it can say that its results turned out to be somewhat unexpected. In the experiment, the $\beta$-effect manifested itself very clearly, PHYSICAL OCEANOGRAPHY VOL. 25 ISS. 5 (2018) 
leading to the intense cyclone formation in the southwestern part of the sea and weakening of currents in its eastern part. According to the observational data [4-6], similar features in the Black Sea circulation are not observed. In [18], data on the greater intensity of the western gyre in the Black Sea are given, but this intensification is not as significant as in the S1 experiment. Additional experiments where the wind intensity and friction parameters at the boundaries of the layers changed, showed that in all cases when the vorticity $\boldsymbol{\tau}$ remained constant in space, the circulation after a certain time turned out to be similar to the circulation obtained in the S1 experiment, where in the southwestern part of the an intense cyclonic circulation was formed.

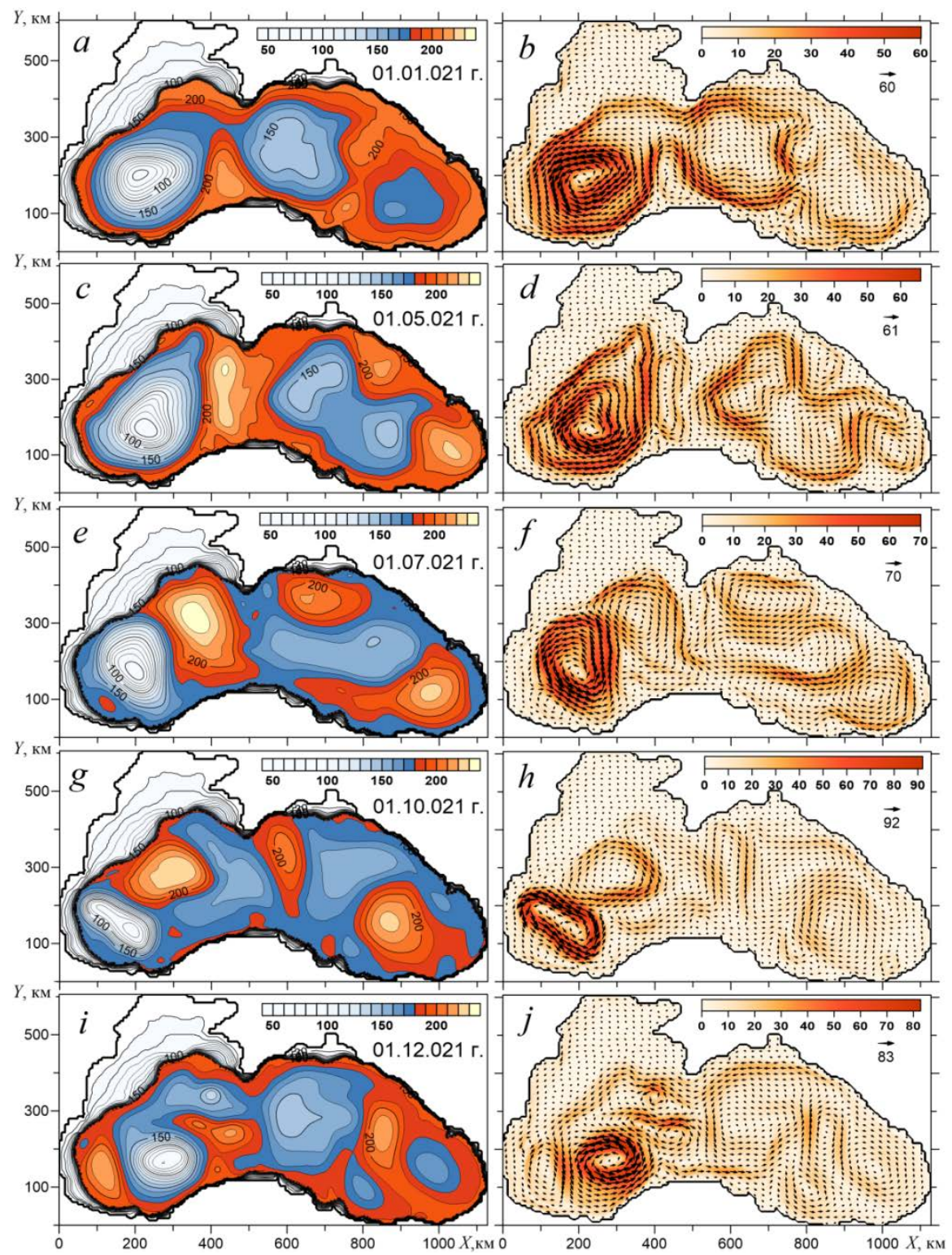

Fig. 4. Instant fields in the $\mathrm{S} 1$ experiment: $h_{1}, \mathrm{~m}(a, c, e, g, i), \mathbf{u}_{1}, \mathrm{~cm} / \mathrm{s}(b, d, f, h, j)$. The dates are given on the maps $h_{1}$; on the maps $\mathbf{u}_{1}$ the scale arrow corresponds to the maximum velocity 
It was suggested that the reason for the discrepancy between the simulation results and observational data can lie precisely in the incorrect specification of the spatial distribution of the tangential wind stress vorticity.

To confirm this hypothesis, the S2 experiment was carried out, where, as mentioned above, the tangential wind stress was set with a vorticity variable in space. In this case, the wind vorticity varied differently over the western and eastern parts of the sea depending on the season (see Fig. $1, d-j$ ). Such wind vorticity distribution is more consistent with the actual atmospheric conditions over the Black Sea, obtained on the basis of observational data and described in [11, 12].

In the S2 experiment, by the fourth year, a circulation is formed in the sea. Its general scheme does not vary in the future until the end of the calculations. As can be seen in the graphs (Fig. 2, c, 2, d), DPE, $K E_{1}$ and $K E_{2}$ fluctuate relative to some average values, which is characteristic of a statistically equilibrium mode. Transitions from one circulation mode to another, as in the S1 experiment, are not observed, although in some years $\left(18^{\text {th }}, 23^{\text {rd }}\right.$ and $\left.33^{\text {rd }}\right)$ such a tendency exists. Note that in these years, $D P E$ and $K E_{1}$ take abnormally low values.

If the instant $h_{1}$ and $\mathbf{u}_{1}$ fields for several consecutive time points for one year are considered, the circulation scheme in the S2 experiment has a great similarity to the circulation observed in the S1 experiment during the first nine years can be observed (see Fig. 3). In the upper layer of the sea along its entire perimeter there is an intensive cyclonic current (analogous to the Rim Current), having the velocities of $60-100 \mathrm{~cm} / \mathrm{s}$, depending on the season. The maximum velocity values are noted in early spring, the minimum ones - at the end of summer. The current has a pronounced meandering character. The intensity and amplitude of the meanders increase in the spring-summer period, especially along the northern sea boundary(Fig. 5, $f, 5, g$ ). In winter, during the period of maximum cyclonic vorticity of the wind, the meandering of the circular current practically terminates (Fig. 5, $a, 5, b$ ).

Throughout the experiment, there is a cyclonic circulation in the lower layer of the sea. There the long-wave oscillations overlap along the isobaths associated with the propagation of trapped waves in the continental slope area and the Rossby barotropic waves in the deep-water part of the basin. Recall that the same wave processes were observed in the S1 experiment during the first 9 years, but then the circulation readjusted (see Fig. 4). In the S2 experiment, a similar readjustment of the circulation does not occur, since the excess cyclonic vorticity of the currents in the southwestern part of the sea is compensated by the anticyclonic vorticity of the wind. In other words, the wind in the western part of the basin has an inhibiting effect on the circular cyclonic current, formed under the action of the cyclonic rot $\boldsymbol{\tau}$ prevailing over the sea. This leads to a weakening of the western intensification of currents. The role of the $\beta$-effect, which manifests in the Rim Current propagation along the entire perimeter of the Black Sea, remains the same as under the stationary wind effect.

In the S2 experiment, the separation of a circular current into two separate cyclonic gyres is periodically observed. In some cases, this occurs when the Rim Current meanders meet and mutually overlap, moving towards each other along the northern and southern coasts (Fig. 6, $a, 6, b$ ). Most often, this overlap occurs in the narrowest place of the Black Sea between Turkey and Crimea (Fig. 6, c-f). Along the southern boundary of the basin, large meanders form less frequently than in the 
north, mainly in summer and early autumn. The overlapping of meanders sometimes occurs in several places at the same time. Then there can be more than two large-scale gyres in the sea for some time.

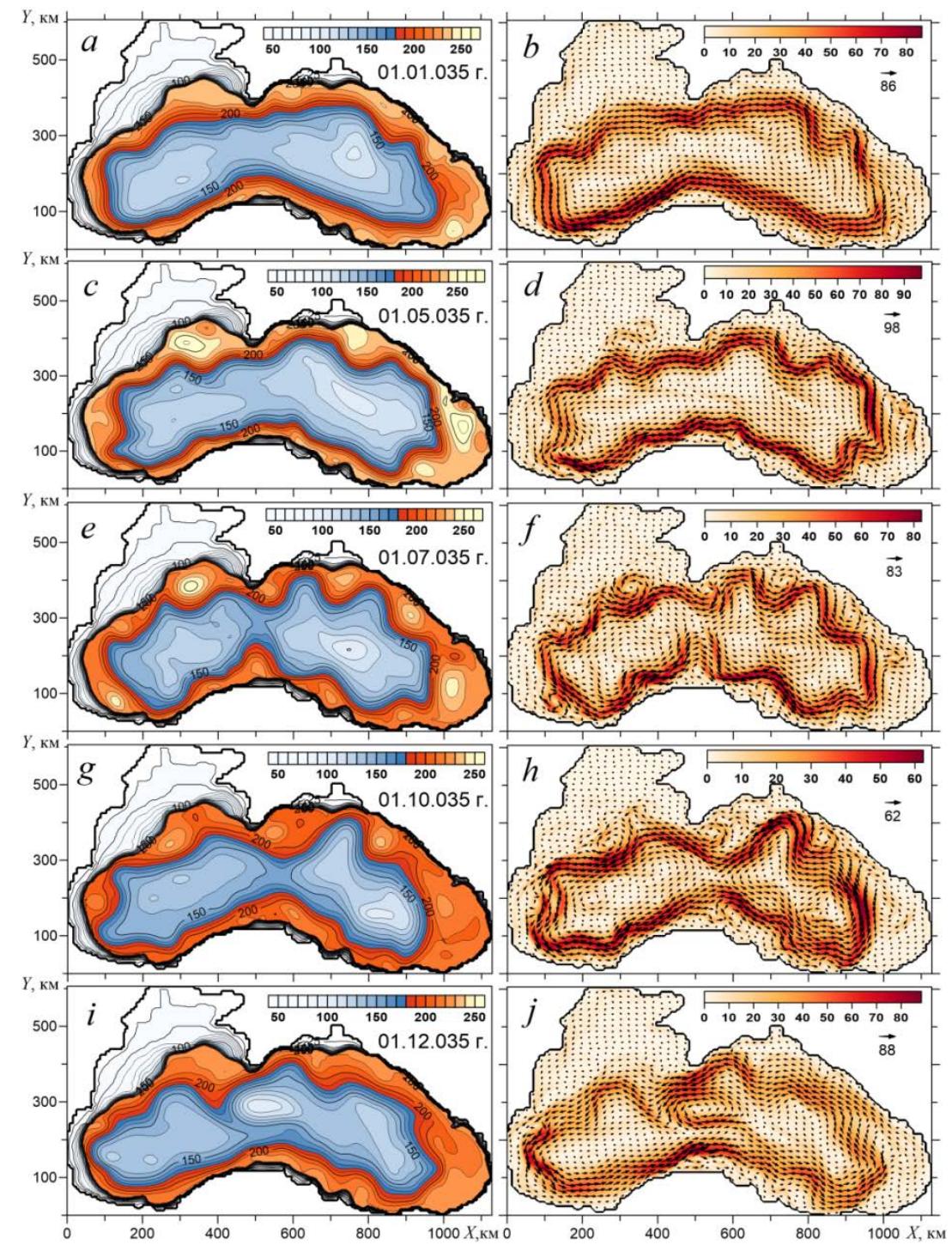

Fig. 5. Instant fields in the $\mathrm{S} 2$ experiment: $h_{1}, \mathrm{~m}(a, c, e, g, i), \mathbf{u}_{1}, \mathrm{~cm} / \mathrm{s}(b, d, f, h, j)$. The dates are given on the maps $h_{1}$; on the maps $\mathbf{u}_{1}$ the scale arrow corresponds to the maximum velocity

In addition, the separation of circulation into two gyres in the S2 experiment occurs when an anticyclonic eddy is formed in the Anatolian coast area (Fig. 6, $g-j$ ). In this case, the separation of circulation is more stable and long lasting. Note that such conditions occur quite rarely, about once every 6-7 years in summer and autumn months. The energy graphs in these years show the maximum values of $D P E$, which indicates a greater potential energy accumulation than in other years in the preceding winter. 


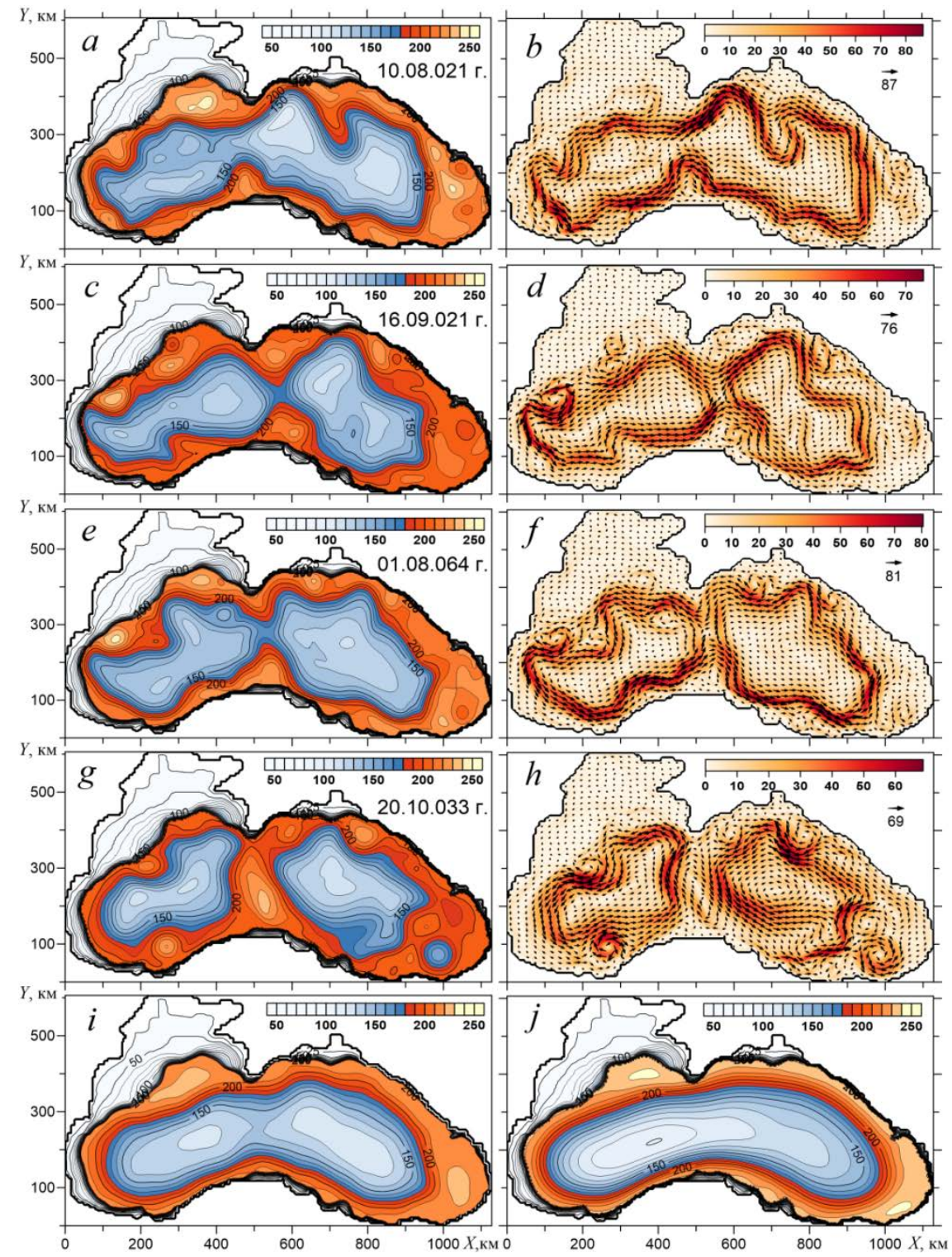

Fig. 6. Instant fields in the S2 experiment: $h_{1}, \mathrm{~m}(a, c, e, g), \mathbf{u}_{1}, \mathrm{~cm} / \mathrm{s}(b, d, f, h)$. Monthly average field $h_{1}$, m, for August in the S2 experiment (i), average field $h_{1}, \mathrm{~m}$ in the experiment with stationary wind $(j)$. The dates are given on the maps $h_{1}$, on the maps $\mathbf{u}_{1}$ the scale arrow corresponds to the maximum velocity

A similar pattern of the large-scale circulation separation was obtained in [19] in a prognostic calculation with assimilation in the model of average annual temperature and salinity profiles. In addition, the results of the study of the Rim Current behavior are in good agreement with the data given in [5, p. 126], where in Fig. 4, $a$, there is a map of the Rim Current core, constructed from the results of synchronous oceanographic surveys for four different years. 
According to the S2 experiment, the average multiyear monthly $h_{1}$ fields were calculated. In Fig. 6, $i$ such a field, built for August, is shown. Two large-scale cyclonic gyres located within a circular current spanning the entire sea can be clearly seen. Actually, these are the classic "Knipovich glasses". For comparison, the averaged $h_{1}$ field obtained in an experiment with a stationary wind (Fig. 6, $j$ ) is given.

\section{Conclusion}

In accordance to the results of numerical experiments, the spatial-temporal variability of the tangential wind stress has a significant effect on the formation of large-scale circulation in the Black Sea. This explains the need of the correct consideration of the wind effect in simulation of large-scale processes in the Black Sea.

In the S1 experiment (without taking into account the spatial features of the distribution of rot $\boldsymbol{\tau}$ ), the resulting pattern of current does not fully correspond to the well-known scheme of the Black Sea circulation, but this experiment shows how atmospheric conditions over the sea can affect the characteristics of largescale currents. Comparison of theS1 and S2 experiments makes it possible to explain the mechanism of the formation of two closes in intensity and structure sub-basin gyres - "Knipovich glasses".

When using wind the vorticity with constant in space (the S1 Experiment), the circulation is divided into two gyres, but it is not entirely correct to call these gyres "Knipovich glasses" because of the extremely intense cyclonic gyre in the southwestern part of the basin, being inherently a western boundary layer in the Black Sea.

The predominance of anticyclonic vorticity of tangential wind stress in the southwestern part of the sea (the S2 experiment) actually leads to a smoothing of the "western boundary layer" and to a qualitative change in the structure of circulation, namely, the appearance of two sub-basin gyres close in intensity, quite reminiscent of "Knipovich glasses". It is necessary to emphasize that the prevalence of anticyclonic wind vorticity in the western Black Sea is a fact that was established based on the observational data analysis $[9,11,12]$.

There are different opinions about the $\beta$-effect influence on the large-scale circulation formation in the Black Sea. Based on the results obtained, it can be affirmed that his role is great. As was shown in [2], and both new S1 and S2 experiments confirmed this, the Rossby waves, formed as a result of the $\beta$-effect and nonlinearity, contribute to the propagation of a circular current (the Rim Current) over the continental slope within the entire Black Sea perimeter.

Absence of the pronounced western intensification of currents in the Black Sea is explained by the spatial distribution of the wind field, under which the intensification of currents near the western coast, resulting from the $\beta$-effect, is compensated by the anticyclonic vorticity rot $\tau$ in this sea area in spring, summer and autumn.

\section{REFERENCES}

1. Pavlushin, A.A., Shapiro, N.B., Mikhailova, E.N. and Korotaev, G.K., 2015. Two-Layer Eddy-Resolving Model of Wind Currents in the Black Sea. Physical Oceanography, [e-journal] (5), pp. 3-21. doi:10.22449/1573-160X-2015-5-3-21 
2. Pavlushin, A.A., Shapiro, N.B. and Mikhailova, E.N., 2017. The Role of the Bottom Relief and the $\beta$-effect in the Black Sea Dynamics. Physical Oceanography, [e-journal] (6), pp. 2435. doi:10.22449/1573-160X-2017-6-24-35

3. Zatsepin, A.G., Kremenetskiy, V.V., Stanichny, S.V. and Burdyugov, V.M., 2010. Basseynovaya Tsirkulyatsiyai Mezomasshtabnaya Dinamika Chernogo Moryapod Vetrovym Vozdeystviem [Black Sea Basin-Scale Circulation and Mesoscale Dynamics under Wind Forcing]. In: A.V. Frolov and Yu.D. Resnyanskiy, eds., 2010. Sovremennye Problemy Dinamiki Okeanai Atmosfery: Sbornik Statey, Posvyashchennyy 100-Letiyu so Dnya Rozhdeniya Prof. P.S. Lineykina [Modern Problems of Ocean and Atmosphere Dynamics. The Pavel S. Lineykin Memorial Volume]. Moscow: TRIADA LTD., pp. 347-368 (in Russian).

4. Ivanov, V.A. and Belokopytov, V.N., 2013. Oceanography of the Black Sea. Sevastopol: ECOSI-Gidrofizika, $210 \quad$ p. Available at: https://www.researchgate.net/publication/236853664_Ivanov_VA_Belokopytov_VN_Oceano graphy_of_the_Black_Sea_National_Academy_of_Sciences_of_Ukraine_Marine_Hydrophys ical_Institute_Sevastopol_210_p [Accessed: 06.09.2018].

5. Blatov, A.S., Bulgakov, N.P., Ivanov, V.A., Kosarev, A.N. and Tuzhilkin, V.S., 1984. Izmenchivost' Gidrofizicheskikh Poley Chernogo Morya [Variability of Hydrophysical Fields of the Black Sea]. Leningrad: Gidrometeoizdat, 239 p. Available at:http://ru.bok.org/book/2974762/202428 [Accessed: 08.09.2018] (in Russian).

6. Korotaev, G., Oguz, T., Nikiforov, A. and Koblinsky, C., 2003. Seasonal, Interannual, and Mesoscale Variability of the Black Sea Upper Layer Circulation Derived from Altimeter Data. Journal of Geophysical Research, [e-journal] 108(C4), 3122. doi:10.1029/2002JC001508

7. Stanev, E.V., 2005. Understanding Black Sea Dynamics: Overview of Recent Numerical Modeling. Oceanography, [e-journal] 18(2), pp. 56-75. https://doi.org/10.5670/oceanog.2005.42

8. Tuzhilkin, V.S. and Kosarev, A.N., 2007. Gidrologiyai Dinamika Vod Chernogoi Kaspiyskogo Morei [The Black and Caspian Sea Hydrology and Water Dynamics]. In: S.A. Dobrolyubov, A.N. Kosarev, eds., 2007. Vodnye Massy Okeanov I Morei: k 100-letiyu A.D. Dobrovol'skogo [Water Masses of Oceans and Seas: To the $100^{\text {th }}$ anniversary of D. Dobrovolskiy]. Moscow: MAKS-press, pp. 208-237 (in Russian).

9. Rachev, N.H., Roussenov, V.M. and Stanev, E.V., 1991. The Black Sea Climatological Wind Stress. Bulgarian Journal of Meteorology and Hydrology, 2(3-4), pp. 72-79.

10. Mihaylova, E.N., Polonskiy, A.B. and Shokurova, I.G., 2013. O Svyazi Intensivnosti Tsirkulyatsii v Chernom More s Zavikhrennost'yu Polya Vetra [About Relationship between Circulation Intensity in the Black Sea and the Wind Field Vorticity]. Ukraïns'kij Gìrometeorologǐ̌nij Žurnal = Ukranian Hydrometeorological Journal, (12), pp. 193-203. Available at: http://uhmj.odeku.edu.ua/o-svyazi-intensivnosti-tsirkulyatsii-v-chernom-more-szavihrennostyu-polya-vetra/ [Accessed: 31.08.2018] (in Russian).

11. Efimov, V.V. and Yurovsky, A.V., 2017. Formation of Vorticity of the Wind Speed Field in the Atmosphere over the Black Sea. Physical Oceanography, [e-journal] (6), pp. 3-11. doi:10.22449/1573-160X-2017-6-3-11

12. Efimov, V.V. and Anisimov, A.E., 2011.Climatic Parameters of Wind-Field Variability in the Black Sea Region: Numerical Reanalysis of Regional Atmospheric Circulation. Izvestiya, Atmospheric and Oceanic Physics, [e-journal] 47(3), pp. 350-361. https://doi.org/10.1134/S0001433811030030

13. Efimov, V.V., Shokurov, M.V. and Barabanov, V.S., 2002. Physical Mechanisms of Wind Circulation Forcing over the Inland Seas. Izvestiya, Atmospheric and Oceanic Physics, 38(2), pp. 217-227.

14. Korotaev, G.K., 2001. O Prichine Sezonnogo Khoda Tsirkulyatsii Chernogo Morya[On a Reason of Seasonal Variation of the Black Sea Circulation]. Morskoy Gidrofizicheskiy Zhurnal, (6), pp. 14-20 (in Russian).

15. Kamenkovich, V.M. and Monin, A.S., 1978. Fizika Okeana. T. 2. Gidrodinamika Okeana [Ocean Physics. Vol. 2, Ocean Hydrodynamics]. Moscow: Nauka, 435p. (in Russian). 
16. Stanev, E.V. and Rachev, N.H., 1999. Numerical Study on the Planetary Rossby Modes in the Black Sea. Journal of Marine Systems, [e-journal] 21(1-4), pp. 283-306. https://doi.org/10.1016/S0924-7963(99)00019-6

17. Kubryakov, A.A. and Stanichny, S.V., 2015. Dynamics of Batumi Anticyclone from the Satellite Measurements. Physical Oceanography, [e-journal] (2), pp. 59-68. doi:10.22449/1573-160X-2015-2-59-68

18. Leonov, A.K., 1960. Regional'naya Okeanografiya. Chast' 1. Beringovo, Okhotskoe, Yaponskoe, Kaspiyskoei Chernoe Morya [Regional Oceanography. Part 1, The Bering, Okhotsk, Japanese, Caspian and Black Seas]. Leningrad: Gidrometeoizdat, 480 p. (in Russian).

19. Lishaev, P.N., Korotaev, G.K., Knysh V.V., Mizyuk, A.I. and Dymova, O.A., 2014. Vosstanovlenie Sinopticheskoy Izmenchivosti Gidrofizicheskikh Poley Chernogo Moryana Osnove Reanalizaza 1980-1993 Gody [Reproductionof Synoptic Variability of the Black Sea Hydrophysical Fields Basedon Reanalysis for 1980-1993]. Morskoy Gidrofizicheskiy Zhurnal, (5), p. 49-68 (in Russian).

About the authors:

Andrey A. Pavlushin - Junior Research Associate, Department of the Oceanic Processes Dynamics, FSBSI MHI (2 Kapitanskaya St., Sevastopol, 299011, Russian Federation), ResearcherID: R-4908-2018, pavlushin@mhi-ras.ru

Naum B. Shapiro - Senior Research Associate, Department of the Oceanic Processes Dynamics, FSBSI MHI (2 Kapitanskaya St., Sevastopol, 299011, Russian Federation), Dr. Sci. (Phys.-Math), ResearcherID: A-8585-2017, n.shapiro@mhi-ras.ru

Eleonora N. Mikhailova - Senior Research Associate, Department of the Oceanic Processes Dynamics, FSBSI MHI (2 Kapitanskaya St., Sevastopol, 299011, Russian Federation), Dr. Sci. (Phys.-Math), e.mikhailova@mhi-ras.ru

Contribution of the co-authors:

Andrey A. Pavlushin - carrying out the numerical experiments, the results processing and analysis, preparation of the article text and graphic material

Naum B. Shapiro - development and improvement of the numerical model used for calculations, the article review and consultations

Eleonora N. Mikhailova - verification of the results obtained, correction of the article text

All the authors have read and approved the final manuscript.

The authors declare that they have no conflict of interest. 